\title{
Occupational differences in disability retirement due to a shoulder lesion: do work-related factors matter?
}

\author{
Maria Sirén $^{1}\left({ }^{\circledR} \cdot\right.$ Eira Viikari-Juntura $^{2} \cdot$ Jari Arokoski $^{1} \cdot$ Svetlana Solovieva $^{2}$
}

Received: 16 September 2019 / Accepted: 24 April 2020 / Published online: 4 May 2020

(c) The Author(s) 2020

\begin{abstract}
Objective To identify occupations with a high risk of disability retirement due to a shoulder lesion and to examine the effect of physical and psychosocial work-related factors on occupational differences in disability retirement.

Methods We followed Finnish wage earners aged 30-59 years $(n=1,135,654)$ from 2005 to 2014 for full disability retirement due to a shoulder lesion. The work-related exposures were assessed with job exposure matrices. We calculated age-adjusted incidence rates and hazard ratios to test for the association between occupation and disability retirement due to a shoulder lesion. We also examined the contribution of work-related exposures to the excess risk of disability retirement.

Results As compared to professionals, the age-adjusted risk of disability retirement was increased among men in all occupational groups except managers and customer service clerks and among women in several occupational groups. Adjustment for education attenuated the occupational differences considerably, particularly among women. The physical work-related factors fully explained the excess risk of disability retirement due to a shoulder lesion among male finance and sales associate professionals and administrative secretaries as well as among agricultural and fishery workers. In women, the physical workrelated factors fully explained the excess risk among construction workers, electricians and plumbers. For both genders, the contribution of psychosocial factors to excess risk of disability retirement was modest and seen for monotonous work only. Conclusions A reduction of the level of physical work load factors as well as monotonousness of work has a potential to prevent work disability due to a shoulder lesion.
\end{abstract}

Keywords Disability retirement $\cdot$ Occupation $\cdot$ Physical work load factors $\cdot$ Psychosocial factors $\cdot$ Shoulder disease $\cdot$ Work disability

\section{Introduction}

Population aging is becoming critical over the next decades (World Report on Aging and Heath 2015), especially in the developed countries, challenging sustainable economy. Therefore, lengthening working careers has been set as a national priority in many countries. Musculoskeletal

Electronic supplementary material The online version of this article (https://doi.org/10.1007/s00420-020-01549-y) contains supplementary material, which is available to authorized users.

Maria Sirén

maria.siren@hus.fi

1 Department of Physical and Rehabilitation Medicine, Helsinki University Hospital, University of Helsinki, Nordenskiöldinkatu 18 A, 00029 HUS Helsinki, Finland

2 Finnish Institute of Occupational Health, Helsinki, Finland diseases, including shoulder lesions, are the leading causes for work disability in Finland (Pekkala et al. 2018). Disability due to a shoulder lesion is faced at working age, since the incidence of specific shoulder diseases peaks at the years between 45 and 65 years (Greving et al. 2012; van der Windt et al. 1995).

An increased risk of specific shoulder diseases has been found in certain occupational groups, including painters (Loew et al. 2019), farmers, forest workers, construction workers (Rolf et al. 2006), nurses (Chung et al. 2013) and meat-processing workers (Frost and Andersen 1999). These studies have linked the increased risk of shoulder diseases to several exposures. Systematic reviews have provided moderate evidence for the association between shoulder diseases and physical work-related factors (especially arm elevation and shoulder load) and weak evidence for psychosocial work-related factors (van der Molen et al. 2017; van Rijn et al. 2010). 
Earlier, we showed that shoulder lesions lead to decreased work participation and preterm exit from paid employment (Siren et al. 2019b). Furthermore, we showed that physically heavy work and working with hands above shoulder level increase the risk of disability retirement due to a shoulder lesion (Siren et al. 2019a). Knowledge on the occupational differences in the risk of disability retirement due to a shoulder lesion and the relative contribution of work-related factors to these differences might help target preventative measures at the workers with the highest risk.

The aims of this study were, first, to identify occupations with a high risk of disability retirement due to a shoulder lesion in the Finnish working population and, second, to examine whether physical and psychosocial work-related factors explain occupational differences in disability retirement.

\section{Materials and methods}

\section{Setting and data sources}

We carried out a longitudinal population-based study, utilizing register data from a $70 \%$ random sample of the Finnish population aged 18-70 years living in Finland on 31 December 2004 ( 2.5 million). Persons aged 30-59 years (as of December 2004), who had gainful job on 1 January 2005, were eligible for the study. We excluded persons, who did not have an occupational title and those who started to receive any retirement-related benefit (full disability retirement, partial or full old-age retirement, or unemployment retirement) before 1 January 2005. Our cohort consisted of $1,135,654$ persons $(574,617$ men and 561,037 women), who were followed from 1 January 2005 till the occurrence of full disability retirement or other pension, death, or end of study period (31 October 2014), whichever came first.

\section{National register of the Finnish Centre for Pensions (FCP)}

Information on employee pensions and earning periods were obtained from the register held by the FCP. The register and work disability pension schemes have been described in detail elsewhere (Gould and Laitinen-Kuikka 2003; Siren et al. 2019b).

\section{Outcome}

The outcome of this study was full time disability retirement (either temporary or permanent) due to a shoulder lesion (ICD-10 code: M75) as the primary diagnosis in the period from 1 January 2005 to 31 October 2014. The FCP register provides information on all disability retirement events with their primary and secondary diagnoses, which are classified according to The International Statistical Classification of Diseases and Related Health Problems, Tenth Revision (ICD-10, Finnish version of ICD-classification 1996).

\section{Risk factor}

Information on persons' occupation held on the 31 December 2004 was obtained from the Finnish Longitudinal Employer-Employee Data (FLEED) of Statistics Finland. The occupations were classified at the four-digit level (including a few occupations coded with 5 digits) according to the Classification of Occupations 2001 by Statistics Finland, which is based on the International Standard Classification of Occupations (ISCO-88, https://www.stat.fi/meta/ luokitukset/ammatti/001-2001/koko_luokitus_en.html). For the analysis, the occupations were aggregated to two-digit level. The description of occupations at the two-digit level has been reported elsewhere (Solovieva et al. 2018).

\section{Mediators}

Physical work load factors (physically heavy work, manual handling of heavy loads (heavy lifting), working with hands above shoulder level, working in a forward bent posture (forward bent posture) and work demanding high handgrip forces) were estimated with a gender-specific job exposure matrix (JEM) (Solovieva et al. 2012). Psychosocial work-related factors (high job demands, low job control and monotonousness of work) were estimated with a genderspecific JEM (Solovieva et al. 2014b).

The JEMs were developed utilizing information on occupational physical and psychosocial exposures collected via face-to-face interviews using validated questions from a nationally representative population survey (Health 2000 Survey 2008). The matrices cover major physical exposures and psychosocial factors at work in 401 and 365 occupations, respectively (covering more than $80 \%$ of all occupations in Finland). Occupations with a small number of respondents and with similar work tasks and exposure profile were grouped (Solovieva et al. 2014a). The physical JEM provides information on the likelihood of exposure (the prevalence of exposure in a specific occupational group). For the analyses, the physical exposures were dichotomized at 0.40 (prevalence of exposure $0-39 \%$ classified as nonexposed $\geq 40 \%$ exposed). The psychosocial JEM contains dichotomized exposure measures. Both matrices showed a fairly good validity (Solovieva et al. 2012, 2014).

\section{Potential confounder}

Information on person's education achieved by the 31 December 2004 was obtained from the Finnish Longitudinal 
Employer-Employee Data (FLEED) of Statistics Finland. Education was categorized as (1) primary (no education after 9 years of compulsory school and sometimes a voluntary 10th year), (2) secondary (11-12 years of education) and (3) tertiary ( $13+$ years of education).

\section{Statistical analysis}

We calculated age-adjusted (age groups 30-39, 40-49, $50-59$ and 60 years) incidence rates (IR per 100,000 person years) of disability retirement due to a shoulder lesion by occupational group and estimated $95 \%$ confidence intervals (95\% CI) using a Poisson distribution. We calculated the confidence interval for the incidence rate by computing the confidence interval from a sample of observations drawn at random from a Poisson distribution as described by Rothman and Greenland (1998).

We used competing risk regression model (stcrreg, STATA version 14) to estimate hazard ratios (HR) and their 95\% CI and to test for the association between occupation and disability retirement due to a shoulder lesion. We accounted for the effect on the outcome of the following competing risks: full disability retirement due to other causes than shoulder lesion, old-age retirement and death. The reference group consisted of professionals.

To quantify the contribution of physical and psychosocial work-related factors to the occupational differences in disability retirement due to a shoulder lesion, we examined, whether the effect of occupation on disability retirement is mediated by those factors.

We assumed that education predetermines the selection of occupation, which in turn predetermines risk factors at work that may cause a shoulder lesion and ultimately result in disability retirement due to this disease. We also assumed that education may be associated with disability retirement directly or indirectly via another pathway than that mentioned above. Since we focused primarily on the contribution of work-related factors, education was considered as a potential confounder in the associations between occupation and disability retirement.

First, we explored the associations between occupation and disability retirement controlling for age (Model 1). After that, we controlled for education (Model 2). The mediating effect of physical and psychosocial work-related factors was tested after the association between occupation and disability retirement was controlled for education. To do this, we included simultaneously into the age and education-adjusted model (Model 2) all physical work load factors (Model 3), all psychosocial work-related factors (Model 4), as well as all work-related (both physical and psychosocial) factors (Model 5).

We also examined separately the contribution of each physical and psychosocial work-related factor to the excess risk of disability retirement. For that, we compared the HR adjusted for age, education and the work-related factor in question with the HR adjusted for age and education (Model 2).

To estimate the contribution of the explanatory factors to the observed statistically significant associations, we calculated the percentage of attenuation of the HR for each occupation (with professionals as reference) after adjustment, using the formula (Hafeman 2009):

$$
\begin{aligned}
\text { PRE }(\%)= & \left(\text { HRModel } \_i-\text { HRModel } \_i+1\right) / \\
& \left(\text { HRModel } \_i-1\right) * 100 \%, \text { PRE } \\
& - \text { proportion explained, } \quad i=1,2 .
\end{aligned}
$$

We used empirical bootstrapping method with 5000 bootstrap samples to estimate $95 \%$ confidence intervals (CI) for the percentage explained.

All analyses were made for men and women separately.

\section{Results}

The overall age-adjusted IR of full disability retirement due to a shoulder lesion was higher for men than women, with 36 (95\% CI 32-39) and 28 (95\% CI 25-31) per 100,000 person years, respectively (Table 1 ). Occupations with a higher IR than the population average included construction workers, electricians and plumbers (men), service workers (women), agricultural and fishery workers (women), craft workers (women), metal and machinery workers (men), chemical, wood- and metal-processing workers (both genders) and unskilled workers (both genders).

As compared to professionals, the age-adjusted risk of disability retirement was elevated in all occupations in women and in all occupations except managers and customer services clerks in men (Tables 2, 3, Model 1). Among men, the highest risk of disability retirement was seen for construction workers, electricians and plumbers (HR 32.5, 95\% CI 20.7-51.2), followed by unskilled transport, construction and manufacturing workers (HR 23.7, 95\% CI 14.5-38.6). Among women, unskilled transport, construction and manufacturing workers had the highest risk of disability retirement (HR 30.9, 95\% CI 17.2-55.6) and chemical, wood and metal workers the second highest risk (HR 30.7, 95\% CI 16.2-58.1).

In both genders, adjustment for education markedly reduced the occupational differences in disability retirement due to a shoulder lesion (Tables 2, 3, Model 2). In men, education explained approximately two-thirds of the risk in most occupations, while in women it explained approximately three-quarters or more of the risk. 
Table 1 Age-adjusted incidence rates (IR per 100,000 person years) and 95\% confidence intervals (CI) of full disability retirement due to a shoulder lesion during 2005-2014 among 30- to 59-year-old men and women by occupational group

\begin{tabular}{|c|c|c|c|c|c|c|c|c|}
\hline \multirow[t]{2}{*}{ Title } & \multicolumn{4}{|l|}{ Men } & \multicolumn{4}{|l|}{ Women } \\
\hline & $N$ total & $N$ events & IR & $95 \% \mathrm{CI}$ & $N$ total & $N$ events & IR & $95 \% \mathrm{CI}$ \\
\hline \multicolumn{9}{|l|}{ Non-manual workers } \\
\hline Managers & 33,383 & 4 & 2 & $1-8$ & 15,887 & 10 & 11 & $5-24$ \\
\hline Professionals & 100,418 & 20 & 3 & $2-6$ & 104,007 & 16 & 2 & $1-5$ \\
\hline Physical and engineering science technicians & 47,831 & 40 & 13 & $8-23$ & 10,771 & 6 & 8 & $2-25$ \\
\hline Environmental officers and nurses & 5540 & 8 & 22 & $8-60$ & 42,905 & 30 & 10 & $5-18$ \\
\hline Finance and sales associate professionals and administrative secretaries & 50,094 & 38 & 11 & $6-19$ & 71,013 & 43 & 9 & $5-14$ \\
\hline Office clerks & 18,259 & 40 & 31 & $18-52$ & 59,621 & 50 & 12 & $8-20$ \\
\hline Customer services clerks & 1608 & 1 & 6 & $1-45$ & 18,005 & 11 & 8 & $3-23$ \\
\hline Service workers & 22,388 & 53 & 31 & $19-55$ & 105,418 & 300 & 42 & $35-52$ \\
\hline Shop workers & 13,412 & 26 & 26 & $13-52$ & 27,982 & 78 & 41 & $29-58$ \\
\hline \multicolumn{9}{|l|}{ Skilled manual workers } \\
\hline Agricultural and fishery workers & 34,521 & 116 & 49 & $36-68$ & 18,297 & 66 & 54 & $35-88$ \\
\hline Construction workers, electricians and plumbers & 47,400 & 301 & 94 & $77-114$ & 2066 & 5 & 39 & $12-131$ \\
\hline Metal and machinery workers & 61,933 & 265 & 63 & $52-79$ & 2958 & 13 & 74 & $35-155$ \\
\hline Craft workers & 11,618 & 37 & 46 & $26-84$ & 6796 & 33 & 72 & $43-127$ \\
\hline Chemical, wood and metal-processing workers & 19,024 & 80 & 59 & $41-85$ & 4259 & 23 & 74 & $38-150$ \\
\hline Machine operators and assemblers & 26,234 & 88 & 49 & $35-69$ & 17,935 & 68 & 55 & $37-85$ \\
\hline Professional drivers & 45,901 & 141 & 46 & $35-63$ & 2667 & 3 & 16 & $2-113$ \\
\hline \multicolumn{9}{|l|}{ Unskilled manual workers } \\
\hline Building caretakers, cleaners, assistant nurses and kitchen workers & 16,440 & 74 & 66 & $46-97$ & 43,971 & 265 & 93 & $75-116$ \\
\hline Unskilled transport, construction and manufacturing workers & 18,613 & 83 & 66 & $45-100$ & 6479 & 37 & 84 & $50-144$ \\
\hline All & 574,617 & 1415 & 36 & $32-39$ & 561,037 & 1057 & 28 & $25-31$ \\
\hline
\end{tabular}

Overall, the combined contribution of physical work load factors was higher than the combined contribution of psychosocial work-related factors in both genders (Tables 2, 3 , Model 3 and 4). In men, the occupations with very high contribution of physical work load factors were agricultural and fishery workers $(82.6 \%, 95 \%$ CI $82.2-83.0)$ and construction workers, electricians and plumbers $(78.4 \%, 95 \%$ CI 78.1-78.8). In women, the highest contribution was observed for construction workers, electricians and plumbers $(91.4 \%, 95 \%$ CI 90.2-92.6). The physical work-related factors completely explained the excess risk of disability retirement among male finance and sales associate professionals and administrative secretaries as well as agricultural and fishery workers. Among female construction workers, electricians and plumbers physical work-related factors accounted for all excess risk of disability retirement. Psychosocial factors had a modest effect in male machine operators and assemblers, professional drivers and unskilled transport, construction and manufacturing workers and female chemical, wood- and metal-processing workers as well as unskilled transport, construction and manufacturing workers. Supplementary Tables 1A and Table 1b show the HR and their 95\% CI for all models.
A composite exposure, heavy physical work, showed the highest contribution to the excess risk of disability retirement in both genders (Tables 4, 5, Supplementary Tables 2A and Table 2B). The proportion of the risk explained was especially high for male agricultural and fishery workers $(86.8 \%, 95 \%$ CI 86.5-87.2) and male and female construction workers, electricians and plumbers $(77.8 \%, 95 \%$ CI $77.4-78.2$ and $85.1 \%, 95 \%$ CI 83.5-86.6, respectively). Among men, at least 50\% of the excess risk of disability retirement was explained by heavy lifting (for agricultural and fishery workers), working with hands above shoulder level (for construction workers, electricians and plumbers) and working in a forward bent posture (for the two above-mentioned occupational groups as well as craft workers). In contrast, none of the specific physical work load factors contributed significantly to the risk of disability retirement among women. Of the psychosocial work-related factors, only monotonous work showed a contribution to the excess risk. This was observed among male machine operators and assemblers, professional drivers and unskilled transport, construction and manufacturing workers and female chemical, wood and metal-processing workers as well as unskilled transport, construction and manufacturing workers. 


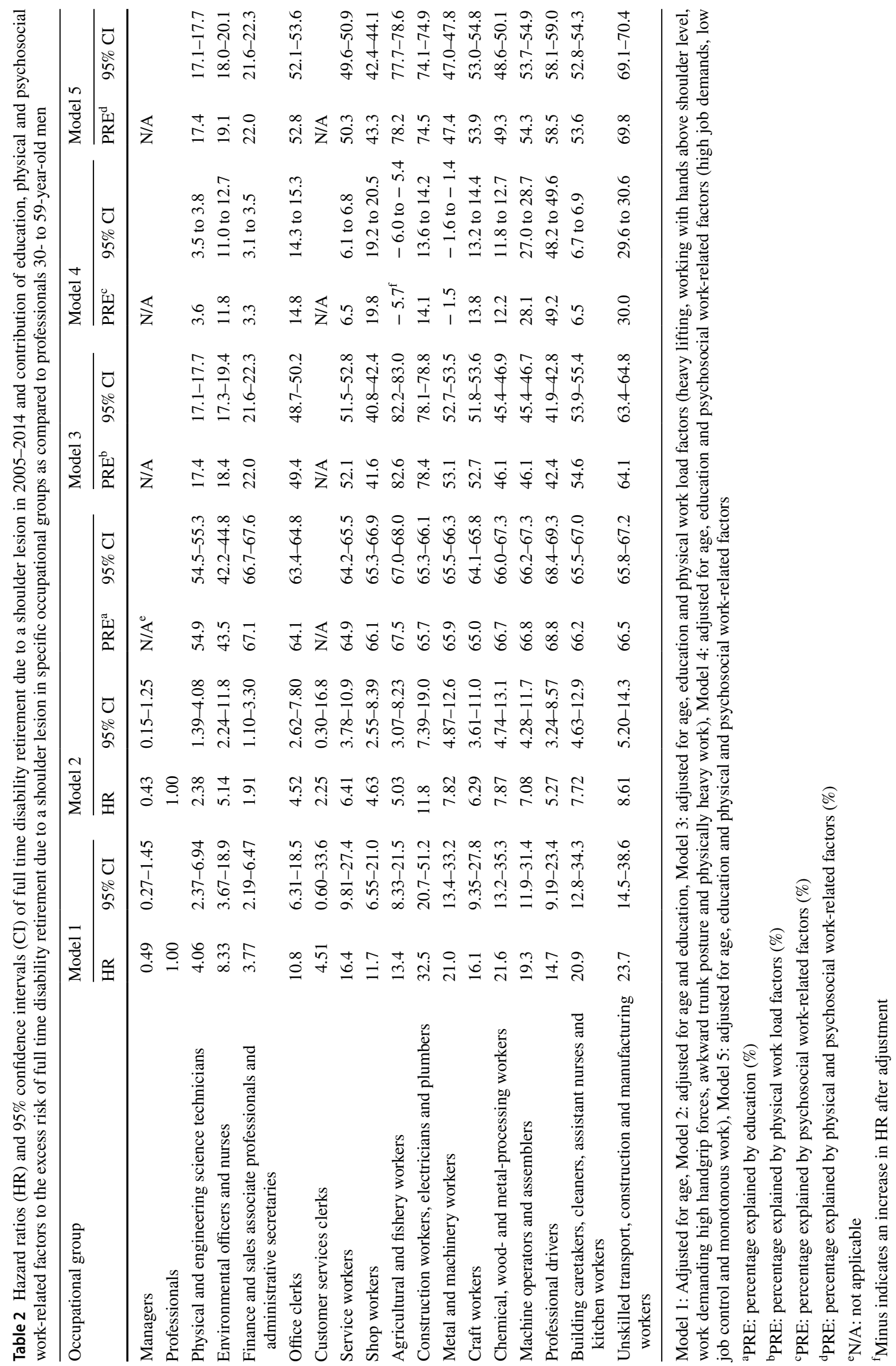




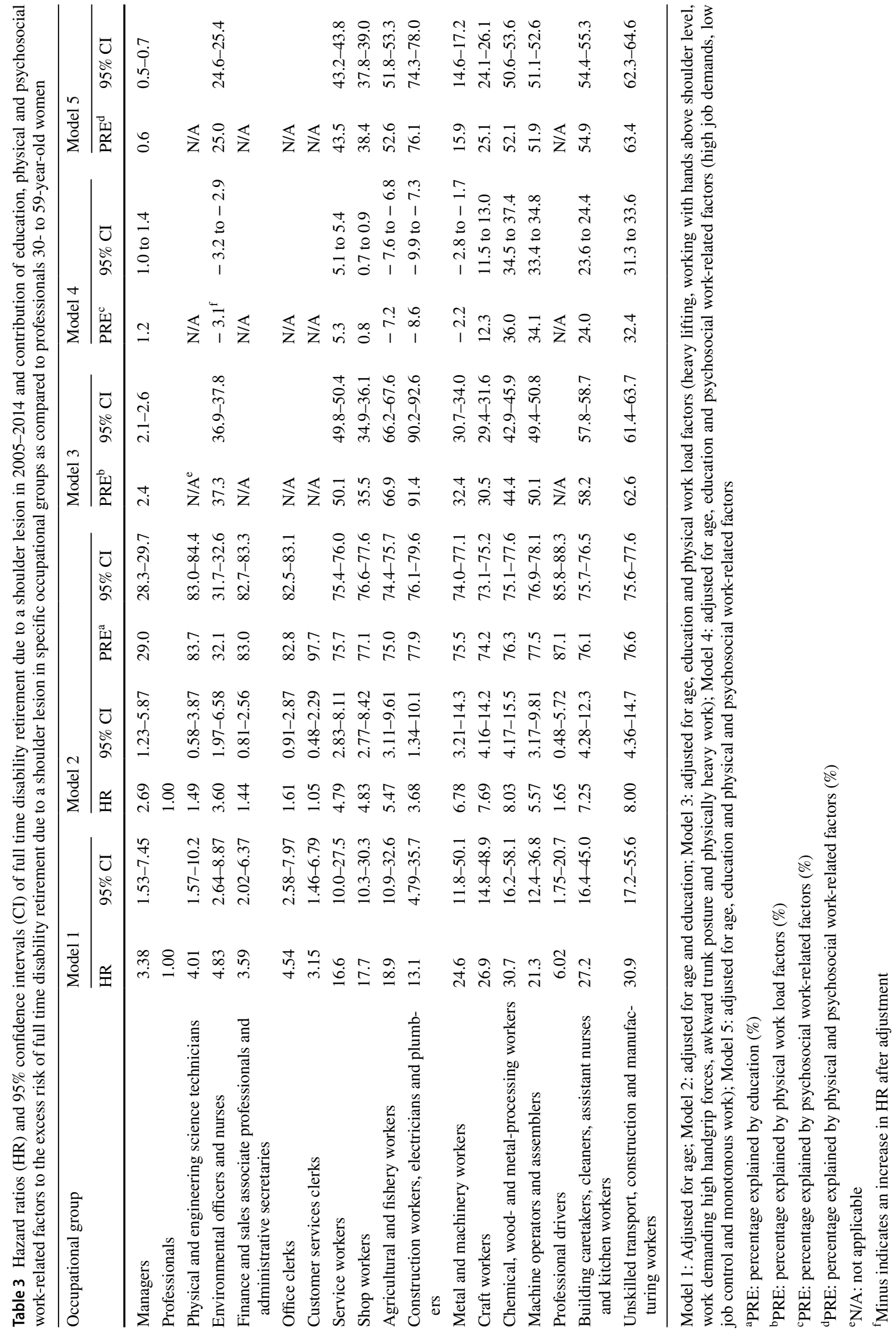




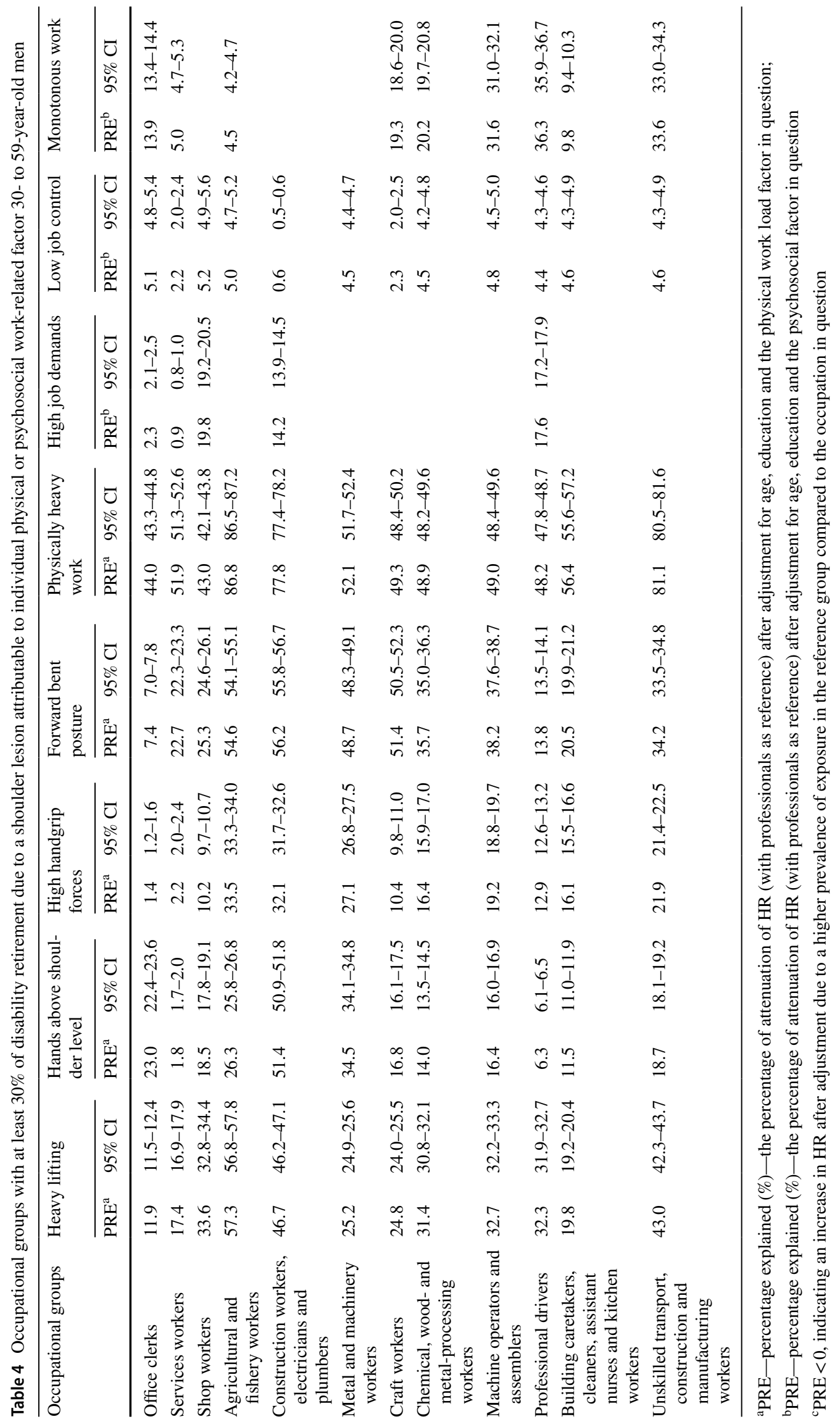




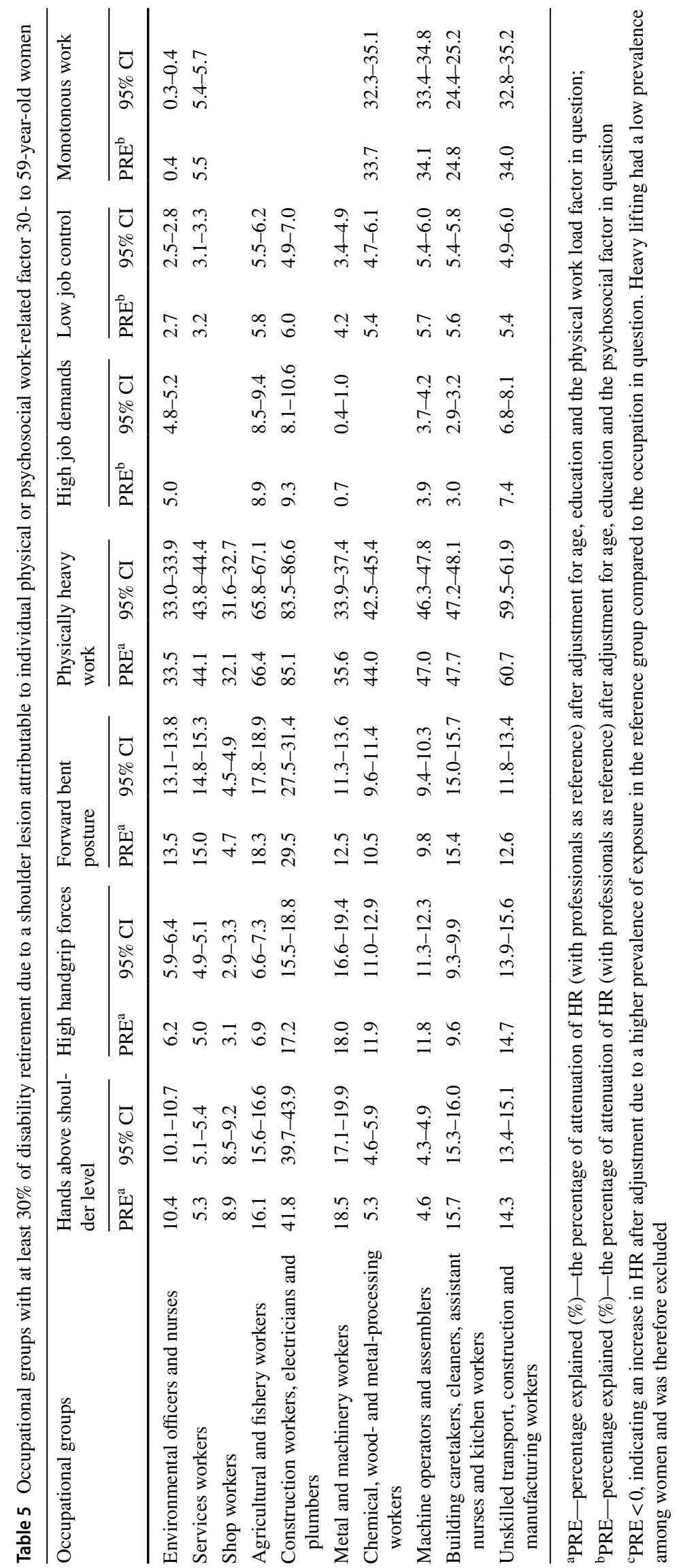




\section{Discussion}

To our best knowledge, this is the first population-based study on occupational differences in disability retirement due to specific shoulder diseases. In men, the highest incidence rate for disability retirement due to a shoulder lesion was seen in construction workers, electricians and plumbers, followed by unskilled manual workers and metal and machinery workers. In women, the highest and second highest incidence rates were seen in unskilled manual workers. As compared to professionals, the age-adjusted risk of disability retirement was increased among men in all occupational groups except managers and customer service clerks and among women in several occupational groups. Adjustment for education attenuated the occupational differences considerably, particularly among women. The physical workrelated factors fully explained the excess risk of disability retirement due to a shoulder lesion among male finance and sales associate professionals and administrative secretaries as well as among agricultural and fishery workers. In women, the physical work-related factors fully explained the excess risk among construction workers, electricians and plumbers. For both genders, the contribution of psychosocial factors to the excess risk of disability retirement was modest and seen for monotonous work only.

There is a growing body of evidence to suggest that shoulder disorders may be increased among some workers (Linaker and Walker-Bone 2015). Previous studies have though reported the incidence or the prevalence of a specific shoulder disease or shoulder pain in selected occupations and have typically provided no gender specific results. In the current study, the outcome was disability retirement due to a shoulder lesion, indicating a more disabling condition. Furthermore, we investigated a broad array of non-manual and manual occupations and quantified the impact of physical and psychosocial work-related factors on the occupational differences separately for the men and women.

Despite the different outcome, our findings are partly in line with the previous studies. For instance, male construction and agricultural workers were over-represented in a German register study on rotator cuff operations (Rolf et al. 2006). Moreover, painters have been reported to have considerably more supraspinatus tears and shoulder pain than controls (Loew et al. 2019) and meat-processing workers to have an increased risk of shoulder impingement syndrome (Frost and Andersen 1999). Furthermore, rotator cuff disease was common in a study on predominantly female nurses (Chung et al. 2013). In line with these results we found a markedly high incidence of disability retirement due to a shoulder lesion among women in the unskilled manual worker group that included assistant nurses as well as in female service workers, including nurses.
Of the physical work-load factors examined in our study, the composite factor of heavy physical work showed the largest contribution to the excess risk of disability retirement due to a shoulder lesion in both genders. Of the specific work load exposures, working with hands above shoulder level and working in a forward bent posture explained at least $50 \%$ of the excess risk in male construction workers. Among male agricultural and fishery workers, heavy lifting and forward bent posture were the strongest contributors to the excess risk of disability retirement. For women the contribution of specific work load factors was rather low. Our findings indicate that workplace interventions addressing at least one physical load factor might substantially reduce risk of disability retirement in men, while in women multiple exposures should be targeted to achieve a reduction in disability retirement.

Of psychosocial exposures, monotonous work was the only single exposure that explained a notable proportion of excess risk of disability retirement due to a shoulder lesion. This was seen particularly in manual occupations, such as machine operators and assemblers as well as professional drivers in men, and in chemical, wood- and metal-processing workers in women. Because of the high contribution of psychosocial factors to excess work disability in male professional drivers, workplace interventions targeted at both psychosocial and physical factors would be the most effective.

Considerable occupational differences in disability retirement due to a shoulder lesion remained after controlling for education and physical and psychosocial work-related factors. The risk of disability retirement was still high among unskilled manual workers and most groups of skilled manual workers. Individual factors, such as obesity, may partly explain the remained occupational differences. However, it has been shown for disability retirement due to musculoskeletal diseases that occupational class differences remain even after controlling for occupational and lifestyle factors (Leinonen et al. 2011).

\section{Strengths and limitations}

We used a large nationwide register-based sample representing the Finnish working-age population and followed the persons for nine years. All disability retirement cases were medically certified, and the diagnoses were classified according to ICD-10. Additionally, due to the large sample size, we were able to look at a wide range of occupations for men and women separately. However, some occupational groups were relatively small and had few events, accordingly these results should be interpreted with caution. Furthermore, by utilizing a gender-specific job exposure matrix for the assessment of physical and psychosocial exposures we eliminated the effect of information bias on the observed associations. 
Some limitations should be, however, taken into consideration while interpreting the results. We were not able to control for individual factors such as lifestyle factors or illness behavior. In addition, we did not have information on previous occupations, or the length of time the jobs were held. A person with a shoulder problem might have changed his job to a less physically demanding one. This may have led to an underestimation of the occupational differences in disability retirement. Finally, using a job exposure matrix to assess psychosocial factors may have resulted in an underestimation of their contribution (Solovieva et al. 2014a).

\section{Conclusion}

The results of this study suggest that heavy physical work and, in some occupations, also specific exposures, such as working with hands above shoulder level, heavy lifting and working in a forward bent posture, are associated with work disability due to a shoulder lesion. Surveillance of work exposures in high risk occupations could identify workers at risk of work disability due to a shoulder lesion. Reduction of the level of physical work load factors as well as monotonousness of work has a potential to prevent work disability due to a shoulder lesion. In highly exposed occupations, such as skilled and unskilled construction workers as well as agricultural and fishery workers in both genders, and female cleaners, associate nurses and kitchen workers, the potential reduction in disability retirement could be remarkable.

Acknowledgements Open access funding provided by University of Helsinki including Helsinki University Central Hospital.

\begin{abstract}
Author contributions All authors contributed to the study conception and design. Material preparation, data collection and analysis were performed by SS. The first draft of the manuscript was written by MS and all authors commented on previous versions of the manuscript. All authors read and approved the final manuscript.
\end{abstract}

Funding This study was funded by NordForsk (Grant number 76659), the Finnish Work Environment Fund (Grant number 115105), the Academy of Finland (Grant number 303534) and by a university-level health research (Helsinki University Hospital/Internal Medicine and Rehabilitation) project (Y101500007) (Grant number HUS/174/2019).

\section{Compliance with ethical standards}

\section{Conflict of interest None declared.}

Ethical approval The study was fully register-based and applied identification numbers pseudonymized by Statistics Finland. Research using such data does not need to undergo review by an ethics committee according to Finnish legislation.

Open Access This article is licensed under a Creative Commons Attribution 4.0 International License, which permits use, sharing, adaptation, distribution and reproduction in any medium or format, as long as you give appropriate credit to the original author(s) and the source, provide a link to the Creative Commons licence, and indicate if changes were made. The images or other third party material in this article are included in the article's Creative Commons licence, unless indicated otherwise in a credit line to the material. If material is not included in the article's Creative Commons licence and your intended use is not permitted by statutory regulation or exceeds the permitted use, you will need to obtain permission directly from the copyright holder. To view a copy of this licence, visit http://creativecommons.org/licenses/by/4.0/.

\section{References}

Chung YC et al (2013) Risk of musculoskeletal disorder among Taiwanese nurses cohort: a nationwide population-based study. BMC Musculoskelet Disord 14:144. https://doi. org/10.1186/1471-2474-14-144

Frost P, Andersen JH (1999) Shoulder impingement syndrome in relation to shoulder intensive work. Occup Environ Med 56:494-498. https://doi.org/10.1136/oem.56.7.494

Gould R, Laitinen-Kuikka S (eds) (2003) Current trends in disability pensions in Europe. In: Proceedings from a seminar held in Helsinki on 8 th April 2003. Finnish Centre for Pensions, Helsinki. http://urn.fi/URN:NBN:fi-fe2015112619981

Greving K, Dorrestijn O, Winters JC, Groenhof F, van der Meer K, Stevens M, Diercks RL (2012) Incidence, prevalence, and consultation rates of shoulder complaints in general practice. Scand J Rheumatol 41:150-155. https://doi.org/10.3109/03009 742.2011 .605390

Hafeman DM (2009) "Proportion explained": a causal interpretation for standard measures of indirect effect? Am J Epidemiol 170:14431448. https://doi.org/10.1093/aje/kwp283

Health 2000 Survey (2008) National Public Health Institute, Helsinki. https://urn.fi/URN:NBN:fi-fe201204193320

Leinonen T, Pietilainen O, Laaksonen M, Rahkonen O, Lahelma E, Martikainen P (2011) Occupational social class and disability retirement among municipal employees-the contribution of health behaviors and working conditions. Scand J Work Environ Health 37:464-472. https://doi.org/10.5271/sjweh.3182

Linaker CH, Walker-Bone K (2015) Shoulder disorders and occupation. Best Pract Res Clin Rheumatol 29:405-423. https://doi. org/10.1016/j.berh.2015.04.001

Loew M et al (2019) Could long-term overhead load in painters be associated with rotator cuff lesions? A pilot study. PLoS One 14:e0213824. https://doi.org/10.1371/journal.pone.0213824

Pekkala J, Rahkonen O, Pietilainen O, Lahelma E, Blomgren J (2018) Sickness absence due to different musculoskeletal diagnoses by occupational class: a register-based study among 1.2 million Finnish employees. Occup Environ Med 75:296-302. https://doi. org/10.1136/oemed-2017-104571

Rolf O, Ochs K, Bohm TD, Baumann B, Kirschner S, Gohlke F (2006) Rotatorenmanschettendefekt-eine Berufserkrankung? Z Orthop Ihre Grenzgeb 144:519-523. https://doi. org/10.1055/s-2006-942240

Rothman K, Greenland S (1998) Modern epidemiology, 2nd edn. Lippincott-Raven, Philadelphia

Siren M, Viikari-Juntura E, Arokoski J, Solovieva S (2019a) Physical and psychosocial work exposures as risk factors for disability retirement due to a shoulder lesion. Occup Environ Med 76:793800. https://doi.org/10.1136/oemed-2019-105974

Siren M, Viikari-Juntura E, Arokoski J, Solovieva S (2019b) Work participation and working life expectancy after a disabling shoulder lesion. Occup Environ Med 76:363-369. https://doi.org/10.1136/ oemed-2018-105647

Solovieva S, Kontio T, Viikari-Juntura E (2018) Occupation, physical workload factors, and disability retirement as a result of hip 
osteoarthritis in Finland, 2005-2013. J Rheumatol 45:555-562. https://doi.org/10.3899/jrheum.170748

Solovieva $S$ et al (2012) Development and validation of a job exposure matrix for physical risk factors in low back pain. PLoS One 7:e48680. https://doi.org/10.1371/journal.pone.0048680

Solovieva $\mathrm{S}$ et al. (2014a) Development of physical and psychosocial job exposure matrices. https://www.julkari.fi/handle/10024 $/ 135076$

Solovieva $S$ et al (2014b) Evaluation of the validity of job exposure matrix for psychosocial factors at work. PLoS One 9:e108987. https://doi.org/10.1371/journal.pone.0108987

van Rijn RM, Huisstede BM, Koes BW, Burdorf A (2010) Associations between work-related factors and specific disorders of the shoulder-a systematic review of the literature. Scand J Work Environ Health 36:189-201 van der Molen HF, Foresti C, Daams JG, Frings-Dresen MHW, Kuijer P (2017) Work-related risk factors for specific shoulder disorders: a systematic review and meta-analysis. Occup Environ Med 74:745-755. https://doi.org/10.1136/oemed-2017-104339

van der Windt DA, Koes BW, de Jong BA, Bouter LM (1995) Shoulder disorders in general practice: incidence, patient characteristics, and management. Ann Rheum Dis 54:959-964. https://doi. org/10.1136/ard.54.12.959

World Report on Aging and Heath (2015) World Health Organization. Switzerland, Geneva

Publisher's Note Springer Nature remains neutral with regard to jurisdictional claims in published maps and institutional affiliations. 